\title{
Real Hacienda y Negocios. García de Salcedo, Oficial Real en Lima (1532-1556)
}

\author{
por Victoria Carmona y Antonio Acosta
}

\begin{abstract}
In the context of the expansion of mercantile capitalism and the transformation of the State during the sixteenth century, this article focuses on the tensions between private interests and those of the Castillian Crown, particularly the work of the Royal Treasury (Real Hacienda) during the Conquest. It examines the case of one of the first royal officials in Peru. The violation of state norms by administrative agents of the monarchy has been treated by different authors from different perspectives. The reason for returning to this issue here consists in observing it as a strategy combined with other mechanisms of profit extraction in the process of the Conquest and in economic activities in commercial and agrarian sectors.
\end{abstract}

I.

Durante el siglo XV importantes cambios demográficos, económicos y sociales ocurrieron en buena parte de Europa, incluido el reino de Castilla. A partir de ellos, el surgimiento de nuevos sectores sociales, especialmente en las ciudades, fue acompañado de una reorganización del poder que transformaría las estructuras políticas medievales. Como trasfondo, lo que se había iniciado era un proceso de acumulación de capital mercantil que iba a desencadenar profundos cambios y reacciones en la esfera de lo político. ${ }^{1}$ En Castilla, a fines del siglo XV, durante el reinado de los Reyes Católicos se inició una concentración del poder en un proceso de centralización creciente de la administración

${ }^{1}$ Sobre la expansión europea, vid. Ruggiero Romano y Alberto Tenenti, Los fundamentos del Mundo Moderno (Madrid 1971) y R. Rosecrance, La expansión en el Estado comercial. Comercio y conquista en el mundo moderno (Madrid 1987).

Jahrbuch für Geschichte Lateinamerikas 36

(C) Böhlau Verlag Köln/Weimar/Wien 1999 
del Estado. El proceso iniciado entonces y acentuado por los Austrias en el siglo XVI, significaba el reforzamiento de la alianza del clero y la nobleza como clases dominantes y su mantenimiento como columna vertebral de una sociedad en la que, de todas formas, comenzaba a apreciarse el ascenso de ciertos sectores del llamado estado llano a algunas esferas del poder. ${ }^{2}$ En el proceso de gestación de las estructuras de lo que se ha dado en llamar Estado Moderno, dos aspectos fueron cobrando creciente importancia para el mantenimiento y la reproducción de una política cada vez más ambiciosa, de un aparato administrativo cada vez mayor y de unos territorios cada vez más extensos: la caracterización política de los servidores de la monarquía y la Real Hacienda. ${ }^{3}$ En relación con el primero de ellos, durante el reinado de los Reyes Católicos y a lo largo del siglo XVI, en diversos ámbitos de la administración castellana se fueron incrementando el número y las funciones de los burócratas, y se reglamentó con más prolijidad su trabajo. En relación con ello y debido a la evolución de la sociedad, los cargos de la administración, tradicionalmente ocupados por miembros de la nobleza, fueron cada vez más cubiertos por elementos "procedentes de la clase media y de los juristas", como sucedió por ejemplo con órganos como el Consejo de Castilla. ${ }^{4}$ Sin embargo, a pesar de estos cambios, en el creciente ejército de servidores del Estado no hicieron sino reproducirse los problemas de venalidad y laxitud que ya estaban extendidos en el aparato administrativo. Contra ellos no dejaron de levantarse importantes voces durante el mencionado período exigiendo la aplicación de principios en el nombramiento y

${ }^{2}$ Antonio Domínguez Ortiz, El Antiguo Régimen: los Reyes Católicos y los Austrias (Madrid 1973), p. 104 y ss. y John Lynch, España bajo los Austrias (2 vols. Barcelona 1982), vol. I, cap. 2.

${ }^{3}$ Cuando se dice "funcionamiento del Estado" se quiere significar: la articulación, el diseño de unos mecanismos e instituciones de poder de los nuevos grupos sociales que emergían del crecimiento medieval tardío en torno a las nuevas monarquías absolutas. Existe una amplia bibliografía sobre la formación del Estado Moderno, remitimos como uno de los textos fundamentales al de José Antonio Maravall, Estado Moderno y mentalidad social, 2 vols., (Madrid 1972). Para una perspectiva general ver V.G. Kiernan, State and Society in Europe. 1550-1650 (Oxford 1980). Para el contexto que interesa a este artículo, ver Horst Pietschmann, El Estado y su evolución al principio de la colonización española de América (México 1989).

${ }^{4}$ Lynch, España (nota 2), vol. I, p. 77. 
fiscalización de los puestos de la administración, que condujesen a la existencia de servidores más capacitados y dedicados a sus funciones. ${ }^{5}$

Otro de los pilares básicos sobre el que hubo de asentarse la nueva estructura del poder y el funcionamiento del Estado fue, naturalmente, la Real Hacienda, sustento de la política imperial. Para transformarla en un órgano más acorde con las necesidades de la nueva situación, la Hacienda comenzó a ser retocada ya por los Reyes Católicos en 1476. Pero fue el propio Carlos $\mathrm{V}$ quien procedió a su más importante reorganización con la creación del Consejo de Hacienda. ${ }^{6}$ Naturalmente, en la gestión de las finanzas reales también adquiría relevancia cuanto se ha dicho acerca de los oficiales o servidores del rey. Las quejas contra la actuación de los oficiales de la Real Hacienda se prodigaron durante el siglo XV pero, por acercarnos a los años a que se refiere este artículo, merece la pena recordar que entre los memoriales que recibió Carlos $\mathrm{V}$ recién ascendido al trono y que le movieron después a reorganizar la Hacienda, había alguno que decía:

"Por todo lo cual, el patrimonio real de estos reinos estaba adeudado y los que lo administraban, y metían mano en la hacienda, hacían grandes patrimonios para sus hijos herederos, y, siendo de baja suerte, se llegaban a los de mejor estado. $Y$ para remedio de ello Su Alteza había hablado con algunos perlados y religiosos y personas de esperiencia y conciencia que no les toca la culpa y negligencia de la dicha desorden, y no se llegó al cabo por su acelerado fallecimiento."7

Es decir, que a comienzos del siglo XVI - y se sabe que también antes - había conciencia del problema que significaba que los que administraban "metieran mano" en la Hacienda, en una plástica expresión que significaba tanto la disposición de fondos reales como propios, como el tener negocios que implicaran intereses contrapuestos a los de la monarquía. Pese a que no quepa definirlo así, esto nos aproxima bastante al fenómeno que en nuestros días se conoce por corrupción, aunque con perfiles diferentes a los que hoy día tiene el

${ }^{5}$ B. González Alonso, "Las Comunidades de Castilla y la formación del Estado absoluto": B. González Alonso (ed.), Sobre el Estado y la Administración de la Corona de Castilla en el Antiguo Régimen (Madrid 1981). pp. 7-56.

${ }^{6}$ M. A. Ladero, La Hacienda Real de Castilla en el siglo XV (La Laguna 1973). Ramón Carande, Carlos V y sus banqueros, 2 vols (Sevilla 1981). La tendencia a la institucionalización de funciones en órganos multipersonales se vio contrarrestada con la creciente delegación de funciones en los secretarios, entre los que destaca Francisco de los Cobos. V. H. Keniston, Francisco de los Cobos. Secretario de Carlos V (Madrid 1980).

${ }^{7}$ R. Carande, Carlos V (nota 6), vol. II, pp. 49-50. 
término y referido sólo a ciertos ámbitos de la administración, como era la Real Hacienda. ${ }^{8}$ En medio de estas decisivas transformaciones que ocurrían en Castilla tuvo lugar la llegada de los europeos a América y algunos de los problemas que había planteados se multiplicaron y agravaron. Fue en algunos de estos planos donde se hicieron evidentes y se reprodujeron las incapacidades del Estado - o las habilidades, si se mira desde la óptica de quienes se servían de su aparato - para disponer de una plantilla de oficiales y servidores eficientes, así como de una Real Hacienda gestionada con pulcritud. En las páginas que siguen se intentará mostrar cuáles fueron los mecanismos de los que se sirvió, desde la administración de Estado, uno de los primeros oficiales de la Real Hacienda en los Andes, el veedor García de Salcedo, para aprovechar las oportunidades que le brindaba el proceso de conquista colonial. Éstas fueron de forma combinada: la expoliación de recursos indígenas en forma de botines de conquista; la apropiación de parte de lo destinado a rentas reales, violando lo legislado en su recaudación; el beneficio de tributo de encomienda; las operaciones en la esfera del comercio; y la organización de una próspera empresa agrícola con la que multiplicó su fortuna. De este modo García de Salcedo contribuyó a la acumulación originaria y a la reproducción del capitalismo mercantil, al tiempo que acentuaba las contradicciones existentes ya en Castilla entre los intereses particulares y los de la monarquía en el ejercicio de su función por parte de muchos servidores de la Hacienda.

II.

Como es bien conocido, para no perder las regalías que pudiera proporcionar la aventura indiana, la corona dispuso que las expediciones de descubrimiento y conquista llevasen oficiales de la Real Hacienda encargados de la recaudación de sus rentas. No obstante, durante la conquista americana la gestión de la Real Hacienda hubo de afrontar algunas dificultades como fueron: la escasez de personas cualificadas para tal función, las condiciones bélicas en que hubieron de desempeñarla y la avidez de riquezas de los conquistadores, entre los que se encontraban generalmente los propios oficiales reales,

${ }^{8}$ Horst Pietschmann, "Burocracia y corrupción en Hispanoamérica colonial": Nova Americana, 5 (Torino 1982), pp. 11-37. 
coincidiendo en ellos su condición privada con la de representación del monarca. Por todo ello, el orden en la recaudación de las rentas y en su contabilidad no fue algo habitual. ${ }^{9}$

En las circunstancias en que se desenvolvió la conquista de las Indias, los momentos iniciales fueron especialmente favorables a que desde la administración se pudieran conseguir ganancias por diversas vías. La organización de la estructura de la Real Hacienda dependió en sus comienzos de los primeros oficiales reales. En los inicios de la conquista andina los únicos oficiales asalariados en la gestión de la Hacienda eran los de Lima; en otros lugares en que se recaudaban rentas reales, los encargados de hacerlo eran oficiales delegados por aquéllos, conquistadores o vecinos de confianza del gobernador o de los propios oficiales de Lima. Los delegados solían pagar un canon a los titulares por ejercer dichos oficios, en la espera de que, a su vez, fuesen rentables. Así, G. de Salcedo, sólo en estos meses de mediados de 1538 nombró, como teniente suyo a un tal Francisco Flores, para la provincia de Puerto Viejo, y a Hernando de Avila, para que ejerciera el cargo en el territorio de la expedición de Alonso de Mercadillo. ${ }^{10}$ Cabe imaginar la baja calidad de la contabilidad llevada por algunos de estos delegados, si se considera que las cuentas de los tres oficiales reales titulares en Lima llevaron años en ser esclarecidas. ${ }^{11}$ Desde la perspectiva del Estado y como consecuencia de las adversas condiciones en que se llevaba a cabo la recaudación fiscal, de hecho se producía una merma en las rentas reales - aunque naturalmente es imposible cuantificarla -, debido a la deficiente gestión de los oficiales, precisamente cuando la política imperial incrementaba sus gastos aceleradamente y cuando en

${ }^{9}$ No hay fundamento para sostener que los primeros oficiales de la Real Hacienda eran "funcionarios especializados", como hace T. Hampe en "El tesorero Alonso de Riquelme y la administración financiera en la conquista del Perú (1531-1548)": Historica, X, no. 1 (Lima 1986) pp. 45-87. Por tratar de un compañero del oficial real que aquí nos interesa, remitiremos a este artículo para algunos acontecimientos que afectaron de forma común a ambos personajes. Por otra parte, ver Mario Góngora, Los grupos de conquistadores en Tierra Firme. 1509-1530 (Santiago 1962).

${ }_{10}$ The Harkness Collection in the Library of Congress. Documents from Early Peru. $1531-1578$ (Washington 1932), pp. 79 y 108. Acerca de los primeros pasos de la Hacienda en Indias, v. Ismael Sánchez-Bella, La organización financiera de las Indias. Siglo XVI (Sevilla 1968). En 1529 concedió poder conjunto a F. Pizarro y a los oficiales reales A. Riquelme, A. Navarro y G. de Salcedo para que ejerciesen por el los oficios que el emperador les había otorgado, Archivo General de la Nación, Lima (abreviado en adelante AGN), Protocolos 153.

${ }^{11}$ En la actualidad preparamos un trabajo sobre este asunto. 
la corte se comenzaban a cifrar esperanzas en las riquezas americanas para complementar lo que Castilla a duras penas podía proporcionar. ${ }^{12}$

Por otra parte, desde los primeros momentos de la conquista, los botines obtenidos de la población nativa y los consiguientes repartos entre la hueste constituyeron la inicial riqueza de los invasores. En este sentido, como en otros, el Tawantinsuyo no fue una excepción, sino el mejor paradigma. Con el fantástico rescate que los naturales entregaron a los españoles para canjear por Atahualpa, más otras cantidades de metales tomadas a los indígenas en los primeros meses de permanencia en los Andes, se procedió a la primera gran fundición de la conquista que ascendió, en cifras oficiales, a algo más de un millón y medio de pesos. ${ }^{13}$ Pero no cabe duda de que esta cifra resulta inferior a la real. Por primera vez en los Andes - pero de igual modo a como había ocurrido en otras expediciones en Indias -, en la distribución del botín se escamoteó a la Hacienda del rey una parte importante e imposible de evaluar del metal requisado, bien directamente o mediante la manipulación del peso y de la ley, y en ello tuvieron mucho que ver los oficiales reales a cuyo cargo estaba la responsabilidad de la recaudación del quinto real. Cieza de León escribe sobre el caso:

“... como se oviese hecho la fundiçion y por la quenta supiesen lo que montava el monton que se avía de repartir, sacados los derechos y costas desto y lo que la conpaña devia y el escaño y otras joyas de gran peso, sin lo que se hurtó, que fue mucho, y sin los çien mill ducados que se sacaron para la jente de Almagro, se repartio lo demas entre el governador e sus conpañeros ... echavan la ley a este oro como cosa de burla, porque mucho que tenia catorze quilates le echavan siete y otro de veynte le ponian diez; la plata por el consiguiente. Fue causa este çeguedad que muchos mercaderes con solamente mercar oro y plata enriqueçieron grandemente ..."14

La gestión de la Hacienda colonial en los Andes comenzaba con prácticas poco escrupulosas que fueron el origen de un funcionamiento de la Hacienda plagado de irregularidades en los años siguientes.

${ }^{12}$ Ver las cifras de lo recaudado correspondiente al Rey y llegado a Sevilla en Earl J. Hamilton, American Treasure and the Price Revolution in Spain. 1501-1650 (Cambridge, Mass. 1934). p. 34. Ver también, por otra parte, Carande, Carlos V (nota 6), vol. I, pp. 448-51.

13 James Lockhart, Los de Cajamarca. Un estudio social y biográfico de los primeros conquistadores del Perú (Lima 1986), vol. I, p. 26. V. Tambien Ldo. G. de Espinosa a F. de los Cobos, 1 de agosto de 1533, en Raúl Porras Barrenechea, Cartas del Perú (1524 -1543) (Lima 1959), p. 65.

${ }^{14}$ Pedro Cieza, Crónica del Perú. Tercera Parte. Ed., prólogo y notas de F. Cantú. (Lima 1987), cap. LII, p. 160. 
Desde Cajamarca, Pizarro decidió pasar a Jauja, para donde hay noticias de que el botín alcanzado pudo haber superado los 300.000 pesos, de los que a la Hacienda habrían correspondido en torno a 60.000 en concepto de quintos. ${ }^{15}$ De Jauja los españoles se dirigieron a Cuzco donde se iba a producir el tercer gran "golpe" en los Andes. La legislación establecía la obligación de reservar al rey en cualquier conquista la mejor pieza, lo cual se aplicaba tanto a joyas como a repartimientos de indios. En el caso de Cuzco, Pizarro anunció que aquel botín, por preverse el mayor de la conquista andina correspondería al emperador. Sin embargo, frente a la riqueza de la ciudad, Pizarro cambió de opinión y la ocupó para tomarla y repartirla. Según Cieza de León, "aviendose robado lo que buenamente se puede creer", se obtuvo un botín en oro y plata que, según las fuentes, osciló entre dos y tres millones de pesos. ${ }^{16}$

En la fundición de Cuzco no estuvieron presentes ni el tesorero Riquelme ni el veedor de Salcedo y Pizarro nombró para reemplazarlos a dos soldados que ya habían sustituido a los oficiales reales titulares en otra acción previa. Aún sin haberse encontrado en la fundición, en mayo de 1543, Riquelme, Navarro y Salcedo escribían a Panamá anunciando que el quinto de la fundición de Cuzco había resultado en 116.000 ps. de buen oro y. 46.000 marcos de buena plata. ${ }^{17}$ Pero, parece probable que estas cantidades no reflejaban el verdadero valor total del botín obtenido en metálico. Y no por haber estado ausentes de la fundición dejaban los oficiales titulares de ser responsables de la Hacienda ante el rey, ni dejaban de obtener beneficios irregulares, como se puede deducir de la información contenida en una querella presentada poco después por el fiscal del Consejo de Indias. La posibilidad de manipular el metal obtenido en un botín por parte de los oficiales reales no terminaba con el acto de la fundición. Había gente beneficiada en el reparto que en un primer momento no traía su plata a quintar y que, más tarde, por las presiones crecientes lo hacían pudiéndose aún entonces manipular el peso y la calidad del metal, con más razón cuanto que era traido

${ }^{15}$ Siguiendo determinadas fuentes Waldemar Espinoza Soriano, La destrucción del Imperio de los Incas (Lima 1977), p. 109, afirma que los españoles hallaron en Jauja 300.000 ps. de oro y 20.000 marcos de plata. No obstante, otros cronistas no hablan de cantidades tan importantes. V. p. ej. Cieza, Crónica (nota 14) pp. 175-177 y 194-5.

${ }^{16}$ Cieza, Crónica (nota 14), cap. LIX, p. 224.

$17 \mathrm{~V}$. "Traslado de todas las partidas de oro, plata y piedras fundidas, marcas y quintas ...", Archivo General de Indias, Sevilla (abreviado en adelante AGI), Patronato, 185-R-10. 
fuera de plazo y sus propietarios podían ser denunciados. Esta fue la razón de que se actuara contra los oficiales reales titulares, en el caso de la fundición de Cuzco, aunque no hubieran estado presentes.

Los escándalos acumulados en las operaciones de manipulación de los metales por los oficiales de la Hacienda llevaron, en primer lugar, al fiscal Villalobos, del Consejo de Indias, a querellarse en 1537 contra F. Pizarro, D. de Almagro, los oficiales reales y otros españoles particulares, "por los muchos fraudes cometidos a la Hacienda" durante los cinco años que llevaban en los Andes en perjuicio del real patrimonio; $y$, en segundo término, a promover desde la corte las primeras investigaciones sobre la gestión de la Hacienda. Por lo que respecta a la querella del fiscal del Consejo, el grueso de la acusación se centraba en el reparto del botín conseguido en la toma del Cuzco. Quizás a partir de informaciones de testigos presenciales y aunque no concordase con las cifras oficiales remitidas desde Perú, el fiscal lo evaluaba en "más de tres millones de oro" y ponía énfasis en que, pese a haber anunciado Pizarro con anterioridad que se destinaría al emperador - junto con la misma ciudad, sus términos e indios -, fue distribuído entre los conquistadores. Según el fiscal, los oficiales reales no sólo dejaron de cobrar lo correspondiente al rey, sino que secretamente habían amenazado a los que recibieron oro y plata en el reparto con que lo habían de dar por perdido al no estar marcado. Así consiguieron que muchos les vendiesen plata y oro sin quintar ni marcar, que volvían a vender a mayor precio al estar marcada. En la operación, los oficiales cobraban el quinto real

"en el mejor oro y plata que avía y tomando el peso de ello muy largo y corriente hasta el suelo en favor de vuestra rreal hacienda y mudando y trocando el oro y plata tomando para si lo bueno y poniendo en lugar de ello otro de menos lei y dandolo por menos peso no tan largo y corriente como lo avian rresçibido y favoresçiendolo el dicho governador"18

He aquí un temprano ejemplo de lo que se puede calificar de manipulación contable para beneficio personal de los oficiales de Hacienda. Tras otros cargos, algunos dirigidos contra el tesorero Riquelme, había uno que aludía específicamente a la responsabilidad del veedor, García de Salcedo. Aunque la conservación de la documentación no es buena, se alcanza a deducir de la acusación del fiscal que los oficiales tuvieron

${ }^{18}$ R. Levillier, Gobernantes del Perú. Cartas y papeles. Siglo XVI (Madrid 1921), tomo II, p. 84. 
mal recaudo en la marca del oro y, en lugar de conservarla en el arca de tres llaves, la dejaron en poder únicamente del veedor, quien permitía que la utilizasen otras personas de poca confianza.

Estas y otras graves acusaciones e informes se fueron acumulando durante los primeros años de la conquista contra los oficiales reales del Perú. De hecho, las irregularidades llegaron a ser detectadas por las primeras inspecciones que se efectuaron, sin que la corona lograse remediar la situación ni se decidiese a sustituir a los mencionados oficiales de la Hacienda. En efecto, como consecuencia de dicha situación y a pesar de las buenas relaciones de Francisco Pizarro en la Corte, Carlos $\mathrm{V}$ no tardó en designar hasta dos misiones que entendiesen en la gestión de la Hacienda. La primera, más específica, fue encomendada al dominico Fray Tomás de Berlanga, obispo de Panamá, y la segunda, más general, al también dominico Fray Vicente Valverde, obispo de Cuzco, ambos como jueces de comisión para tomar las cuentas de los oficiales de Hacienda. Eran estos los primeros intentos de una larga serie que realizaría la corona para conocer y regularizar el estado de la recaudación y gestión de sus rentas. ${ }^{19}$

Ambas visitas tropezaron con dificultades en la relación con F. Pizarro y pusieron al descubierto una amplia gama de graves irregularidades en la gestión de la Hacienda pero, como se adelantó, a pesar de las denuncias realizadas, el Consejo de Indias no llegó a adoptar medidas drásticas para cambiar el rumbo de los hechos. Es cierto que lentamente algunas de aquellas irregularidades se fueron corrigiendo, pero otras se prolongaron a todo lo largo de la colonia. De hecho pasaron a formar parte de una actitud generalizada, tanto en el ámbito de la administración como fuera de ella, que tendió a sacar provecho de los bienes y regalías de la corona dando lugar al fenómeno que se conoce como corrupción.

Otra de las bases de la fortuna de García de Salcedo lo constituyó el tributo de la encomienda que recibió en la conquista. Junto a la plata y el oro obtenidos por los medios expuestos, la acumulación continuada de recursos: metales, mercancías, fuerza de trabajo ... proporcionada por el tributo le permitiría desplegar la actividad económica que desarrolló. Salcedo nombrado, veedor de la Real Hacienda en la capitulación

${ }^{19}$ Sobre estas comisiones de Berlanga, Valverde y la relación con la siguiente del contador A. de Zárate ver Hampe, "El tesorero" (nota 9) y "La misión financiera de Agustín de Zárate, contador general del Perú y Tierra Firme 1543-1546": IberoAmerikanisches Archiv 12 (Berlin 1986). pp. 1-26. 
firmada por Pizarro en Toledo, en mayo de 1529, tuvo de salario de 130.000 maravedíes al año (275 ps. de a $475 \mathrm{mrs}$.) ${ }^{20}$ En fecha muy temprana pero que nos es desconocida, Francisco Pizarro concedió a Salcedo una encomienda en el valle de la Nazca que, según algunas informaciones, a mediados de la década de 1540 tenía, en expresión de las fuentes, "más de 1.000 indios". ${ }^{21}$ Sin embargo, en 1549, la que parecía ser la misma encomienda tenía 1.627 indios al ser tasada en las visitas que ordenó el Presidente P. de la Gasca. Obviamente la primera referencia era, además de vaga, una clara subestimación puesto que, a pesar de que la encomienda se encontraba en la costa donde la disminución de la población indígena fue muy rápida, en 1549 todavía tenía más de 1.600 efectivos. ${ }^{22}$

En 1549 el titular de la encomienda ya no era G. de Salcedo, sino un tal Pedro Gutiérrez, vecino de Los Reyes, quien era hombre de confianza del veedor y con él que hacía negocios al menos desde 1542 . El cambio de titularidad debió producirse a raíz de la promulgación de las Leyes Nuevas, que prohibían que los oficiales reales, entre otras autoridades, fuesen titulares de repartimientos. Esta medida debe entenderse como otro esfuerzo en el camino hacia una profesionalización de los cargos de servidores de la Real Hacienda, alejándolos de las tentaciones proporcionadas por los negocios privados. Para compensar la pérdida de sus encomiendas, los oficiales de Hacienda vieron aumentado su salario a 510.000 maravedís al año (alrededor de 1.100 pesos). Sin embargo, pese a la subida de su salario, las posibilidades de burlar la legislación eran grandes y G. de Salcedo no encontró dificultades para situar al frente de la encomienda a un "hombre de paja" y seguir controlándola por vía indirecta. La encomienda y su tributo, como se verá, continuaron significando un aporte esencial para los negocios del veedor. En 1549 el tributo fue tasado en una de las visitas ordenadas por La Gasca y pese a que el volumen demográfico de la encomienda

\footnotetext{
${ }^{20}$ R. Porras, Cedulario del Perú (Lima 1944), tomo I, pp. 6-7 y 11-12.

${ }^{21}$ Alonso de Riquelme recibió su primera encomienda en agosto de 1534, en Jauja, y depués recibió más indios en 1535, en Cuzco. Ver Bertram Lee, Revista del Archivo Nacional del Peru IV (Lima 1926). Y Rafael Loredo, Los repartos (Lima 1958), pp. 222, 230, 244.

${ }^{22}$ La primera referencia corresponde a R. Loredo en Los repartos (nota 21), p. 224, quien cita textualmente el valle de "Canacha", en lo que podría ser un error de transcripción. El segunda dato se encuentra en M. Rostworowski, "La Tasa ordenada por el Licenciado Pedro de La Gasca (1549)”: Revista Histórica, XXIV (Lima), pp. 53102.
} 
debió haberse reducido, la variedad y el monto de los productos y los servicios que los indios debían aportar eran muy importantes.

Como se adelantó, García de Salcedo llevó a cabo una utilización combinada de cuantas posibilidades ofrecía la colonia para enriquecerse $\mathrm{y}$, aprovechando las facilidades que le proporcionaba su situación, desarrolló una dinámica actividad comercial desde los primeros años de la colonia, aunque no consta que recibiera el mismo tipo de permiso para poder hacer negocios mercantiles que concedió el Consejo de Indias al tesorero Alonso de Riquelme. Es de interés este permiso concedido por la corona a de Riquelme para poder tratar y contratar, porque pone en evidencia que en la mente de las autoridades del Estado ya existía la idea - si bien no se hallaba plasmada en la legislación - de que ciertos cargos, como los de oficiales de la Real Hacienda, no debieran tener participación en la esfera mercantil y que, si la ejercían, debía ser mediante una concesión especial. En la línea de lo apuntado anteriormente, podría decirse que se estaba en los inicios, aunque tímidos, del camino hacia la profesionalización de determinados puestos de la administración. Este camino pudo haber sido promovido por las quejas habidas en Castilla hacia la actuación de los miembros de la Hacienda, dada la importancia estratégica de este órgano del Estado, pero la fuerza de los intereses que actuaban desde el propio interior del aparato estatal hizo que esta senda no llevase muy lejos en los siglos siguientes.

En cualquier caso, desde muy pronto - hay datos para 1534 Salcedo participó en numerosas operaciones de compra y venta de mercancías, por ejemplo, en relación con la organización de expediciones de conquista, como la de $\mathrm{D}$. de Almagro a Chile, o con otras ocasiones. Asimismo mantuvo frecuentes y estrechas relaciones con personajes políticos y prominentes hombres de negocios de estos años, cobrando deudas para ellos, concediendo préstamos o realizando otro tipo de gestiones en cantidades del orden de centenares de pesos. Entre ellos merecen citarse el Ldo. Gaspar de Espinosa, el "factotum" de la llegada española al Perú23, el propio Diego de Almagro ${ }^{24}$, Gonzalo Pizarro y su capitán Hernando Bachicao ${ }^{25}$, los mercaderes Alonso Pérez

${ }^{23}$ The Harkness Collection in the Library of Congress, Calendar of Spanish Manuscripts (Washington 1932), p. 30.

${ }_{24}$ Ibíd., p. 75 y The Harkness Collection ..., Documents (nota 10), p. 101.

${ }^{25}$ AGN, Protocolos 153, ff. 149 y 174. 
de Valenzuela ${ }^{26}$, Alvaro de Illescas o Garci Pérez ${ }^{27}$, entre los más conocidos. $^{28}$

Como es fácil deducir muchas de estas relaciones tenían una dimensión política. En principio podría suponerse que Salcedo hubiera mantenido mejores relaciones con los grupos vinculados a la corte, como el "pizarrista", que con los opositores, como el derrotado Almagro o G. Pizarro. No hay que olvidar que, mientras que F. Pizarro era, por así decirlo, protegido del secretario Francisco de los Cobos y del Cardenal Loaysa desde España, García de Salcedo había sido nombrado, en unión del propio Pizarro, y los otros oficiales reales, encargado de recaudar los derechos de "fundidor y marcador mayor del Perú", por el mismo Cobos, quien a su vez había recibido dicho título de Carlos V. ${ }^{29}$ No obstante, estos estrechos lazos con la corte no fueron obstáculo para que, cuando se presentó la ocasión, también llegara a establecer relaciones con quienes se enfrentaban al monarca. Como adelantamos, el veedor no tuvo inconveniente en ayudar económicamente a quien por entonces era un rebelde en oposición a la autoridad real en la colonia, los negocios eran los negocios, por encima de quien ocupase el poder en un momento dado.

De la gran cantidad de operaciones mercantiles en que Salcedo intervino o tuvo alguna relación merecen destacarse algunas. Así, por ejemplo, citaremos la constitución de una compañía que a principios de junio de 1538 habían formado los mercaderes Baltasar de Torregrosa y Miguel Res, con Beatriz de Salcedo, la mujer del veedor, para comerciar durante dos años, con un capital de 4.000 pesos. En el mismo, Torregrosa participaba con 807 ps.; Res, con 1.193; y B. de Salcedo era la accionista principal con 2.000 ps. ${ }^{30}$ Cabe pensar que su esposa actuaba como persona interpuesta en dicha compañía, dado que se sabe que el veedor se encontraba por estas fechas tan tempranas embarcado en negocios de una relativa envergadura. De no menos interés es el poder que, en mayo del mismo 1543, otorgó el mercader de Lima Luis Suárez a Salcedo para cobrar de los oficiales reales - curiosa situación la de Salcedo en esta operación - el oro, la plata y otras

\footnotetext{
${ }^{26}$ AGN, Protocolos 153, f.146.

${ }^{27}$ AGN, Causas Civiles, leg. 3, $\mathrm{n}^{\circ} 15$; leg. 4, $\mathrm{n}^{\circ}$ 25-B; Protocolos 117 y 118.

${ }^{28}$ Véanse relaciones con otros mercaderes, por ejemplo, en The Harkness Collection ..., Calendar (nota 23), pp. 50 y 84.

${ }^{29}$ AGN, Protocolos, 153.

${ }^{30}$ Ibidem, p. 80.
} 
propiedades que le debían por todas las órdenes de pago emitidas por aquéllos, por préstamos, contratos y albalaes. ${ }^{31}$ Esta operación parece revelar que la Real Hacienda, muy pronto y pese a los grandes botines que se coseguían en los Andes, requirió de la asistencia financiera de algunos comerciantes que, como es de suponer, debían condicionar la independencia de la administración del rey.

A fines de la década de 1540 y sobre todo a comienzos de la de 1550 Salcedo pareciera haber incrementado el volumen y el ritmo de sus actividades comerciales y económicas, en general, posiblemente gracias a la progresiva normalización de la vida social y política en la colonia. En primer lugar, como reflejo del crecimiento de su empresa agrícola - cfr. más adelante - se multiplicaron las ventas de azúcar y conservas en cantidades de hasta más de 500 arrobas al año, como sucedió en 1552 y 1553 a precios que oscilaban entre cuatro y seis pesos la arroba. ${ }^{32} \mathrm{El}$ azúcar era colocado fundamentalmente a confiteros de Lima, pero hay partidas destinadas a Panamá, y otras vendidas a mercaderes que probablemente las sacarían de la capital. En cualquier caso, el veedor comerciaba con muchos lugares de la colonia y a ello obedece, como ejemplo, el poder otorgado a su hombre de confianza, Pedro Gutiérrez, en 1552 para poder comerciar con Arequipa, Potosí y Cuzco. ${ }^{33}$ En relación con Cuzco, merece un comentario la venta, en 1554 , de 267 arrobas de vino blanco a dos compradores de dicha ciudad que podría pensarse procedente de las viñas de su empresa. ${ }^{34}$

Otro reflejo de la buena marcha de su actividad en el sector agropecuario eran las compras de esclavos con destino a su empresa y los negocios con barcos. Como es lógico, Salcedo compraba esclavos varones y jóvenes, entre 20 y 30 años, como los que adquirió en 1551 de los que uno llegó a costarle 600 pesos. ${ }^{35}$ Por otra parte, en 1552 , junto al maestre Juan Vizcaíno que parecía ser copropietario, vendió el

\footnotetext{
${ }^{31}$ Ibidem, p. 136.

${ }^{32}$ AGN, Protocolos 42, 58 y 117. Es importante advertir, primero, que esta no era toda la producción de su ingenio, pues en la contabilidad de la empresa se registran otras ventas efectuadas en el lugar $y$, por otra parte, que esto tampoco era todo lo que Salcedo pudo vender en Lima, pues sólo se han detectado las ventas registradas en algunas notarías. Para aproximarse al total de estas operaciones efectuadas por Salcedo, habría que revisar todas las escribanías.

${ }^{33}$ AGN, Protocolos 42.

${ }^{34}$ AGN, Protocolos 117. No obstante, como se comentará más adelante, en el ingenio se compraba vino en Ica para las misas.

${ }^{35}$ Ibidem.
} 
navío "San Cristóbal" por 1.030 pesos. Pero en octubre del mismo año, Vizcaíno partía hacia Panamá con 57 arrobas de azúcar para vender y 1.131 pesos de Salcedo, con el encargo de comprar "el mejor navío que hallare" para traerlo a El Callao y del cual el veedor sería dueño de la mitad. Los rasgos del activo hombre de empresa en que Salcedo se había convertido eran cada vez más marcados. ${ }^{36}$

Es interesante destacar que en la misma escritura que registraba la citada operación se advertía que, si tal compra no tuviese efecto, Vizcaíno emplearía todo el dinero - el de Salcedo y el suyo - en las mercaderías que le pareciese oportuno cuyos beneficios, una vez colocadas en Lima, se repartirían igualmente a la mitad. En esta línea y dada su cuantía, merece resaltarse que, en octubre de 1552 Salcedo concedió poder al ya conocido Miguel Res, "estante" en Tierra Firme, para que lo pudiese obligar hasta en 15.000 pesos, cifra que indica que la capacidad económica del oficial de la Real Hacienda era realmente importante. ${ }^{37} \mathrm{Y}$ de septiembre de 1553 data la mayor operación comercial que hemos podido registrar, en la que Salcedo vendió a la compañía compuesta por el mercader Gonzalo Hernández y por Antonio de Ribera, una cargazón de "ropa y mercaderías" por valor de 30.500 pesos que le serían pagados de la siguiente forma: 15.000 pesos en cuatro días; 7.750 , en seis meses; y los 7.750 pesos restantes, en un año. ${ }^{38}$ Frente a estas cifras, otros detalles como pequeños préstamos hechos a diferentes individuos - como, por ejemplo, 1.000 pesos a Lucas Martínez de Vegazo en noviembre de 1553 - tienen poca importancia. ${ }^{39}$ A no dudar, G. de Salcedo había llegado a convertirse a comienzos de la década de 1550 en uno de los grandes hombres de negocios del Perú, en una posición - o mejor dicho, gracias a ella estratégica en el aparato administrativo colonial del Estado, y la historia de su empresa agropecuaria no hace más que confirmar este hecho.

\section{III.}

Làs líneas básicas del desarrollo de la agricultura temprana en la costa del Perú son conocidas desde hace años. ${ }^{40} \mathrm{~A}$ partir del impulso

${ }^{36}$ Ibidem.

${ }^{37}$ AGN, Protocolos 117.

38 Ibidem.

39 Ibidem.

${ }^{40}$ Robert Keith, Conquest and Agrarian Change. The Emergence of the Hacienda System on the Peruvian Coast (Cambridge, Mass., London 1976). 
facilitado por las encomiendas con sus tributos en productos y en fuerza de trabajo, desde la década de 1540 , pero sobre todo en la de 1550 y siguientes, se pusieron las bases de una ganadería primero y, enseguida, de una agricultura orientadas comercialmente. Las explotaciones algunas organizadas a partir de la titularidad de encomiendas - fueron inicialmente de tamaño medio y dedicadas a cultivos como trigo, azúcar $y$, con una importancia creciente, de vino. Conforme avanzaba el siglo, estas explotaciones de mediano tamaño, con problemas debido a lo reducido del mercado y a dificultades de capitalización, fueron dejando paso a las haciendas, aunque este proceso no fue general y dependió de las zonas de la costa.

Una de las primeras y más conocidas explotaciones en los primeros años de la colonia en la costa peruana fue el ingenio que el veedor $\mathrm{G}$. de Salcedo tenía en Nazca. La existencia de este negocio del veedor fue recogida en algunas crónicas del siglo XVII y, naturalmente, ha pasado a reflejarse en trabajos de historiadores modernos que han reconocido su importancia. A pesar de ello no se conocen aún sus dimensiones reales y algunas de sus singularidades, que merecen un breve estudio. ${ }^{41}$ Recordemos que Salcedo había recibido una encomienda en la Nazca, una zona donde había fértiles valles. Cieza de León, que estuvo en Perú entre 1548 y 1550 , la describía en estos términos:

"En el principal valle destos de la Nasca (que por otro nombre se llama Caxamalca) había grandes edificios con muchos depósitos, mandados hacer por los ingas ... Y siendo estos valles tan fértiles... se ha plantado en uno de ellos gran cantidad de cañaverales dulces, de que hacen mucho azúcar, y otras frutas que llevan a vender a las ciudades deste reino." 42

Con los recursos proporcionados por el tributo de su encomienda en un área tan fértil, pudo ser Salcedo quien iniciara a los pocos años de disponer del repartimiento, como refleja Cieza, el cultivo de la caña de azúcar y el funcionamiento del ingenio que terminó convirtiéndose en una verdadera empresa agropecuaria. El comienzo de la actividad productiva de azúcar así como las relaciones entre españoles e indios en los primeros años son desconocidas y una de las referencias más tempranas documentadas se remonta a 1546. Merece llamar la atención sobre la fecha, porque suscita la duda de si toda la operación que iba

${ }^{41}$ Keith, Conquest (nota 40) la cita en varias ocasiones. Dice que fue "the largest and earliest of these enterprises which produced sugar", p. 75, aunque en p. 99 la considera una chacra, es decir una de las empresas de tamaño medio.

${ }^{42}$ Pedro Cieza de León, La crónica del Perú (Madrid 1984). pp. 295-6. 
a desarrollarse a continuación no estaría movida por la preocupación originada al conocerse las Leyes Nuevas. Estas, aun siendo contestadas violentamente en los Andes, prohibían que los oficiales reales fuesen encomenderos. En cualquier caso, en 1546 un tal Pedro Suárez compró el "valle del Collao de Lucanas", que eran tierras correspondientes al repartimiento de Caxamalca, en la jurisdicción de la Nazca (posterior corregimiento de Ica) y a las que a veces se alude como el "valle de la Nazca". La compra fue hecha a los caciques de dicho valle con D. Francisco Alimanga a la cabeza, propiedad que comprendía:

"desde el nacimiento del agua que viene al dicho valle y hasta el camino real que llaman del tambo viejo, todas las tierras y heredades que estan inclusas en el dicho término"43

En la venta ya se incluía "un asiento de trapiche ingenio (sic) de azúcar" que tenía (¿el cacique?) en el valle y, ciertamente, en el acto de toma de posesión del nuevo propietario, los caciques tomaron a Suárez de la mano y lo hicieron caminar por ciertos cañaverales y chacras de maíz. El precio pagado a los indios por esta extraordinaria compra fue de 300 puercos, la mitad machos, 1 toro y 200 pesos de oro. Al margen de que aparentemente se trataba de una compra barata, es de destacar que, a poco más de 10 años de la llegada de los españoles a la zona, ya había cultivo de caña y elaboración de azúcar en tierras de los indios del repartimiento de G. de Salcedo quien, probablemente, ya comerciaba con ella. Esto quiere decir que el cultivo debió haberse iniciado algunos años antes, máxime si se tiene en cuenta lo que había en el valle sólo tres años más tarde, como se tendrá ocasión de comprobar. En el documento de venta no se dice quién era Suárez pero, en 1556, a la muerte del veedor $\mathrm{G}$. de Salcedo, en los autos del inventario de bienes del ingenio del que para entonces había sido propietario, se menciona a Pedro Suárez como "su hacedor", es decir, su hombre de confianza. Siendo esto así no es raro que, en 1549, tres años después de la citada adquisición, G. de Salcedo comprase esta gran propiedad a P. Suárez por 1.500 ps., una cantidad no alejada de la que él había desembolsado a los indios. Hasta aquí todo podría parecer normal. Sin embargo, lo extraordinario del caso es que, sólo tres días más tarde de esta última operación, Salcedo vendía la mitad de las tierras - como se comprobará,

${ }^{43}$ Biblioteca Nacional de Lima, A 552. "Extracto de los títulos ..." Los indios pleitearían más tarde pór dichas tierras con los herederos de G. de Salcedo. Agradecemos a Efraín Trelles el gesto de habernos facilitado la información sobre este documento. 
mejor sería decir de la empresa - al mismo Pedro Gutiérrez que le había sucedido en su encomienda, por 24.000 pesos de $450 \mathrm{mrs}^{44}$; lo que quiere decir que el valor total del bien objeto de esta venta era de 48.000 ps. Pero, ¿cómo era posible esta diferencia? ¿Qué encerraban las tierras? Si se observa la descripción efectuada en el trato, Salcedo vendía en 1549 la mitad de:

"las tierras rozadas como por rozar, sembradas de cañaverales como por sembrar, y
con todos los pastos y abrevaderos, más la mitad de 25 negros y 2 negras, entre ellos
uno confitero, 10 caballos, 4 carretas nuevas herradas, 8 bueyes, 6 calderas grandes
nuevas de cobre, 10 quintales de cobre de Castilla en plancha, cobres menudos, todo
lo anexo al ingenio y los puercos que tenía en dicho valle del Collao."

A la vista de la descripción, en primer lugar, resulta evidente que el precio pagado por Salcedo a Suárez tres días antes era ficticio y encerraba sin duda una relación entre ambos en la que el supuesto vendedor no era tal, por no ser tampoco el propietario real de lo que ya podemos calificar de considerable empresa. Por otro lado, el negocio había crecido espectacularmente desde lo que en 1546 todavía se denominaba "trapiche ingenio", a lo que ya en ningun modo admitía el nombre de "trapiche"; no queda más remedio que concluir, en este punto, que ni el gobierno de Gonzalo Pizarro, ni siquiera la guerra entre La Gasca y aquél, habían significado malos años para la empresa, sino todo lo contrario. Por último, aunque podría parecer que ahora el hombre fuerte de la Nasca era Pedro Gutiérrez, que acumulaba la encomienda y el $50 \%$ de tan próspera instalación, comprobaremos que esta apariencia era engañosa.

De entrada, a pesar de que Salcedo declaró en el momento de la venta darse "por contento y pagado" del total, lo cierto es que a su muerte, en 1556 , Gutiérrez sólo le había entregado 10.000 ps y le debía aún 14.000; y ello, al margen del hecho de que la valoración del ingenio en 48.000 pesos seguía siendo aún una subestimación ficticia de cara a la transacción, como lo reconocería el propio Gutiérrez. Firmada la escritura de venta entre el veedor y Gutiérrez, al día siguiente, 19 de marzo de 1549 , ambos procedieron a constituir una compañía para la explotación conjunta del ingenio. En principio, cada uno de los socios ponía en ella su mitad del ingenio, pero Gutiérrez "metía" además su

${ }^{44}$ Inventario de los bienes del veedor García de Salcedo hecho por el muy Magfco. Sr. Lcdo. Altamirano ... AGI, Justicia, 467. Las demás referencias al tema proceden de este legajo. 
trabajo en la administración del negocio; se comprometía a entregar a Salcedo la mitad del tributo de los indios "así del servicio personal como de oro e plata e comida e otras cosas; y aportaba, además, el "servicio, tributos y aprovechamientos" de los indios que tenía en encomienda en el valle de la Nasca. Pese a que hacía aportaciones a las que no estaba obligado, como lo referente al tributo de sus indios, a cambio de todo ello, renunciaba a percibir más del $50 \%$ del beneficio del ingenio y lo hacía en razón de la

"demasía que bale la mytad del dicho yngenio ... que vos el dicho veedor García de Salcedo me vendistes la qual dicha demasía conosco yo el dicho pero gutierrez ser muy grande e confieso que en ello me hizistes muy gran merced e honrra e por ser grande la dicha demasía no tengo de llevar mejora ninguna sino que toda la dicha ganancia se ha de partir de por medio ..."

Por si no quedara claro que Salcedo tenía una posición dominante en la relación, un día después todavía éste firmaba una declaración por la que renunciaba en el futuro a los indios "que antes eran suyos" y se comprometía a que, si vendiera su mitad del ingenio, dejaría libre a Gutiérrez de la obligación de entregarle la mitad del tributo de los mismos. El tono de este documento, aludiendo a derechos sobre parte tributo de una encomienda que no era suya, desvela definitivamente el carácter de "hombre de paja" de Gutiérrez y el auténtico poder de Salcedo sobre la encomienda y la empresa, que quizás se remontaba a antes de su compra a P. Suárez. Es interesante señalar que en la tasa del tributo de la encomienda, en 1549, en la entrada número 23 se decía "Y quando el encomendero estuviere en sus tierras - el qual nunca sale dellas - ...", lo cual abunda en la hipótesis planteada, pues aclara que Gutiérrez ya llevaba viviendo en la zona algun tiempo, quizás efectuando el mismo trabajo de administrador del ingenio al que ahora se había comprometido por escrito.

La idea que se puede adquirir con lo dicho hasta aquí es sólo aproximada de la dimensión y las características de la empresa. Para tener una visión más precisa de su envergadura e importancia es necesario analizar con cierto detalle cuestiones fundamentales como la tierra disponible y ocupada, la mano de obra utilizada, sus instalaciones y bienes y, por último, su operación. En relación con el primero de estos asuntos, las citas de la compra de P. Suárez a los indios (1546) y de la venta de G. de Salcedo a P. Gutiérrez de la mitad del ingenio (1549), referidas más arriba, dan una idea aproximada de que la empresa del veedor no tenía problemas en cuanto a la disponibilidad de tierra para 
su expansión. En ambos documentos se habla de un valle entero, el del Collao de Lucanas, en el término - a veces se le llama provincia - de la Nazca. Esto podría ser suficiente para las necesidades del negocio, al menos desde el punto de vista de los cultivos. En los términos en que se constituyó, la propiedad era difícil de medir y, de hecho, en ninguno de los documentos que se conocen consta medida alguna de su superficie total, ni siquiera en el inventario del ingenio y bienes de Salcedo.

Ni en 1546 ni en 1549 se concretaba qué extensión ocupaba la caña de azúcar, el principal cultivo de la empresa, que ya cubría parte de las tierras de maíz indígenas para surtir al trapiche - y ambos, caña y trapiche, debían existir desde hacía algunos años en el lugar. Sin embargo, en 1556 se sabe que los cañaverales ocupaban diecisiete y media fanegas de tierra, distribuidas en dieciocho suertes, o parcelas, que oscilaban entre media fanega y una fanega y media, cada una. Probablemente por tratarse de tierras ganadas al cultivo de maíz de los indios es por lo que se las describía, por ejemplo, como "fanegas de maíz de sembradura de caña de azúcar". 45

La distribución de las parcelas es difícil de recomponer a partir de las descripciones, pero algunos de sus linderos eran: "el molino de pan moler", "la acequia grande con la que se riegan dichos cañaverales", "la huerta de los pepinos" (debía haber otros sectores de huerta con otros cultivos que se mencionarán), "el camino que va del valle de la Nazca al de Ica", "casas del ingenio hacia donde nace el sol", etc. Por otra parte, las suertes o parcelas no estaban todas en cultivo simultáneamente. Algunas parcelas de media fanega incluso se cultivaban por mitades. En agosto de 1556, de cuando data la descripción, en una suerte de media fanega hacía dos meses que se había cortado la mitad, y la otra mitad, que tenía once meses, estaba por cortar. Del conjunto, había algunas suertes que se habían cortado hacía hasta más de un año; dos se habían puesto en cultivo hacía cinco meses y un año respectivamente; una, de media fanega, se había incendiado hacía meses y no se había vuelto a "aderezar y beneficiar"; y otras se estaban cortando. El ritmo de los cortes y del trabajo parecía constante, lo que da idea de que el

${ }^{45}$ No queda claro cuál es la equivalencia de esta expresión, pero es probable que sean 2.9 hectáreas. Cfr. R. Keith, Conquest (nota 40) p. 170 y Susan E. Ramírez, Patriarcas provinciales. La tenencia de tierra y la economía del poder en el Perú colonial (Madrid 1991), p. 309. 
crecimiento de la caña lo era también gracias al riego facilitado por el sistema indígena de acequias.

La empresa, que se conoce como "el ingenio", no sólo producía azúcar sino que, además de la caña, tenía otros cultivos. Así, disponía de una viña con 660 cepas $^{46}$; un higueral también dividido en partes; tres suertes o pagos de cidrales, sin especificar el número de árboles; algunos granados; y una huerta que no se describe, pero en la que debían cultivarse pepinos, zanahorias y berenjenas, entre otros productos. La alusión a la existencia de olivos y aceite en algunas fuentes no queda refrendada en el inventario de los bienes del que se toman estos datos. ${ }^{47}$ Para estos últimos cultivos no se puede saber la superficie empleada, aunque no parece probable que superase la utilizada para la caña de azúcar.

Pero la tierra que ocupaba el negocio no lo era únicamente para la agricultura, ni se limitaba al valle del Collao. La empresa disponía de una importante cantidad de ganado con fines comerciales que ascendía a 3.300 cerdos "que andan pastando en estos valles del término de la Nazca en todas partes dellos"; 3.240 cabras "en los valles de Tucume y Chilo"; y 184 cabezas de vacuno en el mismo valle de Tucume. ${ }^{48}$ Por la vía de los hechos, más allá de lo que constase en los documentos legales, puede constatarse una vez más que el aprovechamiento de las tierras y los recursos indígenas era muy alto. De todo lo mencionado se deduce que, en este caso, probablemente aprovechando las buenas relaciones que parecían existir con los caciques del repartimiento, el acceso a tierras para satisfacer las necesidades del negocio no era un problema.

Los cultivos de las tierras, el proceso de las cosechas, la elaboración de la producción, el cuidado del ganado y el mantenimiento, en general, de una empresa de tales características y en expansión requería la utilización de abundante mano de obra. En primer lugar, para el ingenio propiamente dicho - aunque no es posible separarlo del conjunto de la explotación - en la tasa del tributo de 1549 se

46 A pesar de lo cual se compraba vino para las misas que oficiaba un Padre Uceda.

${ }^{47}$ Keith, Conquest (nota 40), p. 76.

48 En el inventario de bienes hay dos descripciones del ganado que no se diferencian mucho entre sí y hemos preferido la del "encargado del ganado del veedor", Francisco Fernández. Otra persona, Diego Núñez de La Algaba, mencionaba entre los valles en que se encontraba el ganado, además de los citados, los de Copara y Comulgo (?). 
destinaban cincuenta indios ordinarios de la encomienda, que ya era de P. Gutiérrez, renovables cada quince días. En principio se destinaban a

"las cosas façiles y de menos trabajo del dicho yngenio senbrar la caña benefiçiarla y cogerla y juntarla en la chacara para que la puedan llevar las carretas y para ayudar a carretear y a arar si el encomendero quisiere";

todo ello porque el ingenio "redunda en benefiçio a estos reynos y no ayudando los dichos yndios a el se perdería". No hay duda de que los intereses de García de Salcedo eran respetados en Lima por el Ldo. La Gasca. Estos indios no recibían salario pero, en "recompensa" de ellos, el repartimiento se ahorraba - siempre siguiendo la tasa - otros cuarenta indios que tenía que enviar a Lima a cultivar quince fanegas de maíz y trigo ${ }^{49}, 400$ pesos en oro o plata y, además, el encomendero debía emplear en ellos cien vestidos de algodón de los 500 que el repartimiento tenía estipulados en la tasa. Resulta difícil calcular el coste ahorrado por la empresa con los cincuenta indios cuyos salarios no tenía que pagar, del mismo modo que también lo es valorar algunas de las compensaciones, pero podría rondar los 1.000 pesos. Por otro lado, el repartimiento tenía fijado contribuir con treinta indios para el cuidado del ganado, además del encargado que tenía la empresa para tal fin. Señalemos por último que con estas asignaciones de la tasa del repartimiento, que se encuentran también en otras tasas de estos años, se había logrado una fórmula para poder seguir disfrutando del servicio personal indígena aún después de haber sido prohibido en las Leyes Nuevas. Además, ocasionalmente, cuando los caciques no podían cubrir los 1.000 pesos en oro o plata que tenían tasados, pagaban la diferencia en indios alquilados al ingenio. Así sucedió en 1552 en que sólamente entregaron 260 ps. y el resto en indios, aunque no se especifica a cuánto se alquilaba cada uno, ni a qué actividad se dedicaban.

Al margen de lo establecido expresamente en la tasa, no se puede descartar que otros indios realizaran diferentes tareas dentro de la actividad general de la empresa. Así, por ejemplo, "en el puerto de la mar de este valle del Collao" - desde donde se embarcaban productos del negocio a diversos destinos - había una casa-almacén que era custodiada por "un indio principal y otros indios". Por esto, y quizás por otros servicios, aparecen en la contabilidad de la empresa en diversas ocasiones partidas de regalos a los caciques de la encomienda que llegaban a ascender a centenares de pesos. Así, por ejemplo, en 1551 se

\footnotetext{
${ }^{49}$ Supuestamente del encomendero, pero probablemente de García de Salcedo.
} 
emplearon en Lima 210 pesos para "vestidos de caciques"; en 1552 se gastaron también en Lima 276 pesos para caciques y yanaconas, más otros 150 en "cosas" para el cacique D. García y sus principales; o, en 1553, se ocuparon 220 pesos en 20 arrobas de vino blanco para dar a los caciques y algunos negros enfermos. ${ }^{50}$

Además de los indios, la empresa tenía esclavos. En 1549 ya se mencionaban 25 negros, uno de ellos confitero, y dos negras. Pero siete años más tarde la cifra ascendía a cincuenta y seis, de los que cincuenta eran hombres y seis mujeres. Acerca de sus edades sólo se sabe que, de éstos últimos, dos eran niñas pequeñas, a uno se le calificaba de "chico" y a otros dos de "viejos". ${ }^{51} \mathrm{Al}$ margen de otros datos de interés sobre su origen geográfico y otras circunstancias personales, merece destacarse que a veintidós varones se les adjudicaba una actividad específica. En algunos casos eran tareas no cualificadas como: "ayuda en la fragua" o "anda con las carretas"; pero en otros parecía haber cierta especialización, como: "maestro de azúcar", "oficial carpintero", "oficial herrero", "tonelero", etc ... Parece claro que existía una diferencia entre los trabajos "más fáciles" realizados por los indios y los de algunos negros esclavos que, al menos sobre el papel, ejercían las mismas actividades que las del tercer componente de la fuerza de trabajo de la empresa: la mano de obra de blancos.

No resulta fácil precisar el número de peninsulares empleadas en el negocio porque oscilaba dado que a veces los períodos de contratación eran cortos, pero en 1556 probablemente no pasaban de diez. Algunas de sus ocupaciones parecían especializadas, pero otras no tanto. En distintos momentos aparecen un ollero (ganando 300 pesos/año), un carretero (400 ps./año), un cañaverero ( 250 ps./año), uno "que anda con las carretas" (230 ps./año), un hortelano (200 ps./año), un tonelero (200 ps./año), uno que "sirve de andar con los indios" (150 ps./año), un "mandador" y otros. Ocasionalmente, a algunos de estos empleados se les entregaban ciertas cantidades de vino o azúcar como complemento en especie a su salario en dinero, con lo que se daban casi todas las formas posibles de relaciones de producción en dimensiones relevantes para el proceso productivo. Entre 1555 y 1556 la empresa había contado con un administrador, además de P. Gutiérrez que parece que había

${ }^{50}$ Inventario ... (nota 44 ) fols. $12,17,25 \mathrm{v}^{\circ}$ y 26 .

5! Keith, Conquest (nota 40), p. 76 menciona que, durante su rebelión, Hernández Girón había tomado 40 esclavos del ingenio. De ser esto cierto, se habría alcanzado la cifra de 80 ó 90 , lo que parece una cantidad muy alta. 
ejercido ese papel hasta entonces. Estos datos indican que se había alcanzado no sólo una apreciable especialización en el trabajo, sino también un alto grado de organización del mismo. En total se empleaba una abundante mano de obra. En 1549: 80 indios (que, aunque quizás en menor número, ya debían estar trabajando antes), más 27 esclavos (que no debieron aparecer de súbito), más unos cinco europeos sumaban no menos de 110 personas. En 1556, un cierto número mayor de indios, los 56 esclavos, más otros dos en un barco de la empresa y algunos blancos más hacían subir la cifra de los ocupados a no menos de 150 personas, que era una cifra extraordinaria en un sólo negocio para el lugar y la época.

Acorde con el volumen de mano de obra ocupado era el tamaño y la variedad de las instalaciones y equipamiento de que disponía el llamado ingenio. En el Apéndice destacan los abundantes y variados equipos y utensilios para la elaboración tanto de azúcar, como de confitura y conservas. La diversificación y especialización de la actividad de la empresa se refleja, además de en los instrumentos y utensilios generales, en la existencia de las llamadas "casa de confitura", "casa de conservas" y "casa de purgación del azúcar". Pero lo que indica que se está ante un negocio de envergadura son los talleres, es decir las "casa de herrería" y "casa de carpintería". La existencia de la fragua pero, sobre todo, la variedad de instrumentos y herramientas, la cantidad de hierro y cobre confirma que se trataba de una empresa con un alto grado de autonomía y capaz de afrontar una coyuntura adversa como pudo haber sido la rebelión de F. Hernández Girón. Interés especial merece la propiedad, compartida con el maestre, de una nao que permitía a la empresa no sólo el abastecimiento de sus necesidades (lo que ayuda a explicar la abundancia de material, herramientas, esclavos ..., para lo cual la actividad comercial de Salcedo era una indudable ventaja), sino también el transporte de sus ventas a media o larga distancia por vía marítima: Arequipa, Lima, Chile o Panamá. Este hecho reforzaba la capacidad operativa de la empresa aumentando su competitividad. El navío era utilizado también a título personal y no exclusivamente como medio de transporte de la empresa, por el veedor G. de Salcedo.

El negocio estaba creciendo evidentemente desde los inicios de la conquista - aunque no se puedan establecer las fases de su expansión -, continuaba haciéndolo a comienzos de la década de 1550 y Salcedo no dejaba de invertir en el equipamiento de la empresa. En varios años para los que se conserva contabilidad se efectuaron frecuentes 
y diversas compras de materia prima, componentes, o directamente "bienes de equipo". En 1554, por ejemplo, se compraron 10 quintales y 2 arrobas de hierro, a 25 pesos/quintal, por 263 pesos, y se continuaban construyendo calderas para la elaboración del azúcar, como una grande que hizo un tal Castillo, campanero, cobrando 110 pesos. Asimismo se compraban herramientas, elementos para las carretas y negros, que se traían no sólo de Lima, sino también de Cuzco.

La producción era fundamentalmente agropecuaria y dirigida al mercado, pero las ventas no se componían exclusivamente del producto del negocio, sino que incluían bienes aportados por los indios de la encomienda y eran registradas en la contabilidad. El producto principal era el azúcar que oscilaba a veces, por razones que no son claras, entre 4 y más de 6 ps./arroba en períodos tan cortos como dos meses, quizás dependiendo de las existencias o de los clientes. Pero también se vendían derivados del azúcar y otros productos, tales como diacitrón (de 8 á 9 ps./arroba), confitura ( 7 ps./arroba), conservas de berenjenas o zanahorias ( $8 \mathrm{ps} . /$ arroba), canelón de naranja, calabazate, pepinos, culantro, anís ... La empresa tenía además ganados que, en menor proporción que la producción agrícola, también formaban parte de las ventas y uno de los animales que se vendían eran cerdos. Por el contrario y, a pesar de que el inventario de bienes refleja la existencia de 184 vacunos, se estuvieron comprando con frecuencia algunas cabezas que, en ocasiones, se especificaba que eran con destino a las carretas. Por otra parte también se registran en Cargos, o ingresos, los productos de la venta de mantas o piezas de ropa. Dado que cerdos y textiles eran algunos de los componentes de la tasa de los indios de la encomienda, esto último nos indica que se está ante la transformación directa del tributo - pura renta feudal - en ingreso de la cuenta de explotación de una empresa que buscaba la acumulación de beneficios. De todos modos, cabe decir que se trata de una explotación bastante compleja, con un alto grado de diversificación y especialización dentro del proceso productivo, considerando la época, y disponiendo de un muy apreciable nivel tecnológico en su maquinaria e instrumental. Algo difícil de cuantificar es la cantidad total de producto vendido; había mucha venta al menudeo que no aparece cuantificada en peso en las cuentas. Además el veedor extraía grandes cantidades de producto no siempre registrado. De todos modos, y en una tendencia ascendente, el ingenio estuvo vendiendo pronto por cantidades próximas a las 1.000 arrobas, únicamente refiriéndonos al azúcar. A ello habría que añadir cantidades 
también importantes, de centenares de arrobas, de los demás productos arriba relacionados a compradores que eran en su inmensa mayoría españoles, pero entre los que no faltaron ocasionalmente indígenas.

García de Salcedo murió en 1556 en posesión de una gran fortuna. Las irregularidades que cometió como veedor le llevaron a ser objeto de inspección en algunas de las operaciones de control ordenadas por la corona. En 1544 Agustín de Zárate, que le tomaba cuentas y que detectó algunas de aquéllas, no siguió adelante con su tarea por temor a que Salcedo "sobornase con 50 castellanos a un arcabucero que me echara una pelota por el cuerpo", lo que da idea del grado de influencia que había alcanzado el veedor y del temor que despertaba. ${ }^{52}$ En $1549 \mathrm{La}$ Gasca ajustó una "composición" entre García de Salcedo y el contador Juan de Cáceres con la corona, mediante la cual y a cambio de 100.000 pesos los dos oficiales se hacían cargo del alcance de 83.000 pésos hecho al tesorero Riquelme, con el compromiso del Consejo de Indias de no investigar su origen. ${ }^{53}$ Que Salcedo y Cáceres aceptaran asumir dicho déficit implicaba un reconocimiento de corresponsabilidad en el asunto que confirmaba, pero al mismo tiempo condonaba oficialmente, las irregularidades de Salcedo en su gestión en la Hacienda.

Salcedo llegó a formar parte, junto a otros miembros, de la primera clase de peninsulares en los Andes, que controlaban la mano de obra indígena, la tierra y que intervenían en el comercio tanto en el interior del territorio conquistado, como con Panamá y la Península. Muchos de ellos eran tanto simples conquistadores particulares, como por ejemplo Lucas Martínez Vegazo; otros estaban vinculados a la administración colonial, como los Pizarro o el compañero de Salcedo, el tesorero Alonso Riquelme; y los había que eran miembros de la institución eclesiástica, como el arzobispo Jerónimo de Loaysa. Como es sabido, este grupo no era completamente homogéneo y mantuvo violentas pugnas internas, aunque este problema no sea objeto de estudio en estas páginas. ${ }^{54}$

${ }^{52}$ Agustín de Zárate a S. M. Lima, 25 enero 1544. AGI, Justicia 1072.

${ }^{53}$ AGI, Justicia 486.

${ }^{54}$ Ver Efraín Trelles Arestegui, Lucas Martínez Vegazo, Funcionamiento de una encomienda inicial. (Lima 1983); Rafael Varón Gabai, La ilusión del poder. Apogeo y decadencia de los Pizarro de la conquista (Lima 1996); T. Hampe Martínez, "El tesorero ..." (nota 9); Antonio Acosta, "La Iglesia en el Perú colonial temprano. Fray Jerónimo de Loaysa, primer obispo de Lima": Revista Andina, Año 14, no. 1 (Cusco 1996), pp. 53 -71 . 
Por otra parte, G. de Salcedo y los demás oficiales reales, desde su posición y con su actuación en la Real Hacienda, contribuyeron a crear y consolidar en los Andes unas pautas de comportamiento, violando las normas establecidas en la legislación, que se prolongaron en el tiempo y que tenían su correlato en otros ámbitos de la administración, hasta el punto de que en la Península no faltaban cómplices y beneficiarios de esta situación. Naturalmente estas pautas experimentaron modificaciones con los cambios que se fueron produciendo en la estructura económica colonial, pero estas violaciones fueron la vía que el Estado tuvo que aceptar para poder continuar recibiendo las rentas que generaban las colonias, hasta tanto no se emprendieran iniciativas para intentar cambiar el orden de las cosas.

\section{APENDICE: INVENTARIO DE BIENES DEL INGENIO}

/:93 v./ \# Primeramente cinco calderas grandes de cobre asentadas en las hornallas donde se cuece el caldo del azúcar. \# Tres calderas de cobre. La una grande y dos pequeñas <para> que se cueza en ellas melado. /:94/ \# Cuatro tachas de cobre en que tiemplan el melado. \# Un fondo de cobre que está puesto por tacha donde tiemplan el melado. \# Siete repartideras de cobre con que echan el caldo de una caldera en otra. \# Cuatro espumaderas de cobre con que espuman el caldo. \# Tres cazos de colar para echar el melado en las formas. \# Más otro cazo chiquito, todos de cobre. \# Una tacha pequeña de cobre. \# Otra tacha de cobre vieja. \# Otra tacha mediana. \# Un rodo de hierro de sacar carbón. \# Un rodezno y un peón y una rueda grande y otra pequeña y dos ejes; todo de guarango y herrado con planchas de hierro y armaduras con que está moliente y corriente el molino, sin que le falte nada. \# Dos prensas de palo con sus cajas herradas como han de estar, con cuatro cajas. \# Un cuchillo con su puerca. \# Dos martillos de orejas para quietar y poner las prensas.

Casa de herrería. \# Unos fuelles con sus cañones y las herramientas siguientes. /:94 v./ \# Primeramente cuatro pares de tenazas grandes. \# Un espetón de hierro. \# Otro par de tenazas. \# Siete martillos de hierro grandes. \# Otro martillo de hierro pequeño. \# Dos tornillos de hierro grandes. \# Otro par de fuelles con sus cañones. \# Otros dos cañones de fuelles sin ellos. \# Un tas y un yunque grande y dos bigornias, una grande y otra pequeña. \# Una clavera de hierro de hacer clavos de carreta. \# Dos claveras de hacer clavos de herrar. \# Otras dos claveras de hacer clavos para el ingenio. \# Un repartidor de hierro. \# Una tajadera de hierro. \# Dos limas cuadradas de acero grandes. \# Otras cuatro limas pequeñas y unos alicates de cerrajería y un bruñidor. \# Dos guijos grandes de hierro para los ejes. \# Cuatro dientes de la rodezuela pequeña del ingenio. /:95/ \# Un martillo de hacer fondos de caldera. \# Tres (...?) de cajas de hierro en que exprimen el bagazo, nuevos (?) \# Unas tijeras grandes de cortar hierro. \# Un ancho de hierro de maza de carreta. \# Cuatro (. . .?) de hierro nuevos de carreta. \# Dos argollas tobas (?) de hierro 
para negros. \# Un cincho de hierro de eje de carreta. \# Dos fondos de cobre de caldera, viejos. \# Un calzo de hierro viejo. \# Una olla grande de cobre. \# Once abrazaderas de carretas, de hierro nuevas grandes y chicas. \# Otra clavera grande. \# Dos tobillos de hierro y una zurradera de lo mismo. \# Una casa de la dicha fragua en donde está armada y con sus puertas con su llave. \# Un compás de hierro.

Casa de carpintería. \# Cinco hachas de carpintería. \# Otras dos hachas de cortar leña. \# Tres azuelas de trabajar con ambas manos. 1:95 v./ \# Otra azuela de ambas manos. \# Cinco escoplos de hierro y acero. \# Dos compases grandes; el uno (...?) y el otro hembrado. \# Dos escofinas de hierro. \# Dos limas de carpintería. \# Otra lima francesa. \# Dos gurbias c grandes de hierro y acero. \# Tres gurbias c pequeñas. \# Ocho barrenas grandes. \# Tres martillos; el uno macho grande de hierro. \# Dos barretas de hierro; una grande y otra pequeña. \# Tres formones de hierro chicos. \# Once barrenas chiquitas y medianas. \# Unos tapiales de palo. \# Otras dos barrenas chicas. \# Otras dos barrenas; una grande y otra pequeña. \# Un formón chiquito y un escoplo chico y largo. \# Tres sierras braceras; dos grandes y una pequeña. \# Cuatro sierras otras de mano pequeñas y grandes. 1:96/ \# Otra sierra francesa. \# Una almádana c de hierro grande. \# Dos junteras. \# Dos cepillos. \# Tres azuelas de mano pequeñas. \# Dos cuñas de hierro grandes. \# Una azuela de mano de tonelero. \# Una sigura (?) \# Un machete. \# Un compas.\# Una azuela gurbiada grande. \# Una plana y una chajeta $c$ del oficio de tonelero. \# Una sierra. \# Una plana de trabajar de hierro. \# Otra plana de hierro.

Casa de carretería. \# Seis ruedas de carretas; las dos acabadas de hacer y las cuatro que se estaban haciendo y por acabar. \# Otras dos ruedas de carreta viejas. \# Un eje del ingenio con sus guijos que está por acabar. \# Otro palo para un eje. \# Veintisiete camas de carreta. \# Siete carretas que andan al trabajo de la hacienda; las dos nuevas y las cinco viejas. /:96 v./ \# Tres carretas viejas que dice que no sirven por ser viejas y malas. \# Una piedra de amolar con su ciguñuela c vieja.

Casa de la confitura (declaración de Pedro Gutiérrez). \# Una caldera grande de cobre en que se cuece la miel y confites. \# Otra caldera grande toda de una pieza de cobre. \# Una payla de cobre grande. \# Tres tachas de cobre que sirven en la casa de conservas. \# Tres paylas con que labran la confitura. \# Una tacha grande de cobre. \# Dos medias naranajas de cobre medianas. \# Cinco cazos de la confitura. \# Dos espumaderas de cobre medianas. \# Cincuenta planchas de cobre. \# Un paño de cobre. \# Un almirez de metal. \# Una romana de pesar. \# Un peso de pesar. \# Treinta pesos desbaratados con su marco c /:102/ \# Veintiseis petacas de almendras confitadas con sus zozonas (?) cosidas y liadas. \# Noventa petacas medianas llenas de confituras y conservas cubiertas sin zozonas (?), de anís, culantro, canelón, diacitrón, zanahoria, berenjenas y agros (?) \# Cincuenta barriles de media arroba de toda conserva. \# Cuatro barriles medio quintaleños de almendra por confitar algodonada c \# Siete barriles de arroba de conserva en caldo. \# Un cajón de palo que tendría hasta una arroba de canela poco más o menos. \# Noventa panes de azúcar blanco. \# Cinco barriles de dieciocho libras de conserva en caldo.

Casa de Pedro Gutiérrez. 1:97/ \# Una mula rucia vieja del servicio del ingenio. \# Un caballo castaño tuerto que traje $\mathrm{c}$ el vaquero. \# Otro caballo castaño oscuro que anda en el dicho servicio. \# Otro caballo castaño de la propia suerte para el dicho servicio. \# 
Una cadena de hierro con cinco colleras. \# Media arroba de acero. \# Una guindaresa c del ingenio. \# Cincuenta machetes de cortar caña. /:97 v./ \# Veintidos hachas de cortar leña. \# Seis podaderas. \# Seis hoces de segar. \# Ocho cadenas. \# Cuatro rejas. \# Un herramental sin bigornia porque está puesta en la memoria del herrero.

Heredades. \# Una heredad de viñas que está junto al dicho ingenio con 660 cepas más o menos. \# Un molino moliente y corriente con una barra grande que sirve en el dicho molino y en el dicho ingenio y picadera. \# Un higueral de higueras dividido en partes. \# Tres pagos de cidrales que no se sabe los pies que son. \# Algunos pies de granados que estan derramados por la dicha huerta y viñas. \# Un barco con todos sus aparejos marcado que está en la ciudad de Los Reyes, con dos negros ... el maestre -Baltasar Vicentetiene la tercera /:98/ parte ... está fletado para Arequipa. \# Dos negros que estan en el barco: Anton y Perico.

\# Dieciocho suertes de caña de azúcar, de entre media y una fanega y media cada una, que suman diecisiete fanegas y media ¡existe una descripción detallada de cada una.

Negros. \# Un negro llamado maestre Juan, maese de azúcar de tierra de Santo Tomé. \# Otra negra Ines, su mujer, con dos hijas suyas; la una será de tres años y la otra que anda a los pechos y le da leche. \# Otro llamado Francisco Charcas, maestro de echar azúcar, de tierra Congo. \# Justa, mujer del dicho Francisco, de tierra Berbesí. \# Diego, oficial carpintero, de tierra Congo. \# Lanzarote, oficial herrero de tierra Nova, que es negro viejo. \# Junon que sirve en el dicho ingenio, de tierra Biafara. \# Diego, calderero espumador de las calderas /:98 v./ de tierra de Santo Tomé. \# Manuel que bate en las tachas de azúcar, de tierra Congo. \# Gasparillo que es espumador de las calderas del dicho ingenio, de tierra Gelose. \# Grabiel que anda con las carretas, de tierra Congo. \# Juan, tonelero, criollo nacido en Santo Domingo. \# Antón, hortelano, de tierra Angola. \# Antón Guaragora que sirve en el dicho ingenio de aserrador, de tierra Biafara. \# Juan Çancalongo que sirve en la hacienda de prensero, de tierra Biafara.\# Cristóbal, de tierra Biafara, viejo. \# Antón, de tierra Angola. \# Un viejo llamado Ambo, de tierra Ambo. \# Pedro, de tierra Gelose. /:99/ \# Juan, de tierra Barbesí. \# Francisco, de tierra Jolofo (?). \# Sebastián, de tierra Bian. \# Antón, de tierra Berbesí. \# Jorge, de tierra Mosamo (?). \# Pedro Agüero, de tierra Gelosee.\# Otra esclava llamada Barbola, de tierra Berbesí.\# Tomás, que ayuda en la fragua, de tierra Bañol (?).\# Diego, serrador, de tierra Mariango. \# Andrés, ollero, de tierra Nova. \# Otro negro, Andrés, chico, ollero, de Mariango. \# Antón, de tierra Nova. \# Andrés, espumador de las calderas, de tierra Canario. \# Duarte, espumador de tierra Biafara. \# Juan, de tierra Maçambique c \# Juan Barba, de tierra Congo, carretero. \# Antón Muzo (?), de tierra Biafara./:99 v./ \# Perico Tornabay, de tierra Gelosee. \# Andrés, cojo de pie, de tierra Bran (?) \# Juan Bachiller, de tierra Nova. \# Antonia, criolla. \# Pedro Canario, criollo. \# Juan Bañol, de tierra Bañol. \# Pedro, confitero, criollo. \# Pedro, tonelero, criollo, nacido en Lima. \# Juan, de tierra Mandinga. \# Hernando, de tierra Mulare. \# Otro negro que anda huido llamado Pedro, Maçambique, del que no se sabe desde que huyó hará año y medio. \# Juan, que es carretero criollo. \# Juan de tierra ... ?/:100/ \# Andrés, de tierra Mandingo \# Juan, de tierra Brand. \# Alonso, de tierra Nova, que está tullido y no puede trabajar. \# Pedro de tierra Congo. \# Gonzalillo que es loco, de tierra Congo. 
Bienes. \# Un peso de palo de pesar azúcar sin pesas. \# Dos campanas grandes que estan en la iglesia del dicho valle de la Nasca. \# Otra campana pequeña que está en el ingenio, con que llaman a la gente.

Casa de conservas. \# Treinta y siete tinajones, tinajas, tinas y pilones de todas suertes y géneros de conservas, en caldo y fuera de él, y en salmuera y conservada y por conservar, que se estaban haciendo; algunas llenas y otras no tanto, y medias.

Casa de purgación de azúcar. /:101/ \# Los pilones de azúcar. \# Ciento cuatro panes de azúcar blanco. \# Diez panes de azúcar de espumas y respumas c \# Doscientos sesenta y seis panes de azúcar que estan puestos en sus pilones y barbacoas purgándose. \# Doscientos sesenta y seis panes de azúcar de espumas que se están purgando en sus pilones y barbacoas. \# Cincuenta y dos panes de azúcar de respumas que estan purgándose en sus pilones y barbacoas.

Ganados. \# 3.300 cerdos. \# 3.240 cabras. \# 184 vacunos. \# 47 bueyes. 
Brought to you by | Biblioteca de la Universidad de Sevilla Authenticated

Download Date | 3/11/16 2:04 PM 